\title{
Expeditious Syntheses to Pharmochemicals 1,3-Dihydroxyacetone, 1,3-Dichloro-, 1,3-Dibromo- and 1,3-Diiodoacetone from Glycerol 1,3-Dichlorohydrin Using Homogenous and Heterogenous Medium
}

\author{
Fernanda Priscila N. R. da Silva, ${ }^{a}$ Priscila F. dos Santos, ${ }^{a}$ Sara R. B. da Silva ${ }^{a}$ and \\ Vera Lúcia P. Pereira ${ }^{\circledR} * a$ \\ ${ }^{a}$ Laboratório de Síntese Estereosseletiva de Substâncias Bioativas, \\ Instituto de Pesquisas de Produtos Naturais, Universidade Federal do Rio de Janeiro, \\ 21941-902 Rio de Janeiro-RJ, Brazil
}

\begin{abstract}
New efficient and reproductive routes to production of 1,3-dihydroxyacetone (1), 1,3-dichloroacetone (6), 1,3-dibromoacetone (7) and 1,3-diiodoacetone (8) from glycerol 1,3-dichlorohydrin (3) were developed. The synthesis of $\mathbf{1}$ was processed in three steps from glycerol $\mathbf{2}$ (1,3-selective chlorination of $\mathbf{2}$ to $\mathbf{3}$, oxidation of $\mathbf{3}$ to $\mathbf{6}$ and subsequent di-hydroxylation) in $51 \%$ overall yield. On the other hand, 7 and $\mathbf{8}$ were produced from $\mathbf{3}$, via a trans-bromination and trans-iodination, respectively, followed by oxidation and hydroxylation steps, in $38-52 \%$ overall yield. It was used homogeneous media with different reagents $(\mathrm{HCl} / \mathrm{AcOH}$, pyridinium chlorochromate (PCC), $\mathrm{PCC}-\mathrm{HIO}_{4}$ ) and heterogeneous media with reagents supported on polymer resins such as Amberlyst ${ }^{\circledR}$ A26-HCrO ${ }^{4-}$ form, PV-PCC (polyvinyl-pyridinium chlorochromate) and Amberlyst ${ }^{\circledR}$ A26-OH ${ }^{-}$form or reagents supported on alumina such as $\mathrm{KI} / \mathrm{Al}_{2} \mathrm{O}_{3}, \mathrm{KBr} / \mathrm{Al}_{2} \mathrm{O}_{3}$, in solvent free conditions.
\end{abstract}

Keywords: glycerol, PV-PCC, polymer-supported reagent, trans-halogenation, 1,3-dihaloketones

\section{Introduction}

Glycerol (2) is a co-product of the biodiesel manufacture which is produced in $10 \% \mathrm{~m} / \mathrm{m} \cdot{ }^{1-6}$ Its application in the chemical industry is very diverse, for example, it is used in the production of explosives, dyes, polymers, lubricants, inks, papers, synthetic intermediates for fine chemicals. Furthermore, it is used in the pharmaceutical, cosmetic and food industries. ${ }^{4}$ Due to increase of the biodiesel production in the global market, it is estimated that in 2020 the production of glycerol reaches approximately four billion liters. ${ }^{7}$ Despite the diverse glycerol uses, its growing production could cause an excess in the market and an incalculable damage to the environment could be produced if inadequate glycerol disposal was carried out. ${ }^{1-12}$ Thus, it is necessary to develop new strategies to add value to glycerol. Use of glycerol for the production of oxidized compounds such as 1,3-dihydroxyacetone (1,3-DHA (1)) is of great industrial interest. ${ }^{1-6,13,14}$ The 1,3-DHA is naturally found in sugar cane and beet. ${ }^{15,16}$ It has a great use as

*e-mail: patrocinio.ufrj@gmail.com pharmochemical in the cosmetic, pharmaceutical, fine chemical and food industries. For example, it is utilized as active principle in tanning lotions and in the treatment of vitiligo besides, to be employed as a monomer in diverse polymeric biomaterials. ${ }^{17-19}$

Until now, industrial production of compound $\mathbf{1}$ is carried out directly from glycerol through microbiological fermentation using Gluconobacter oxydans. ${ }^{20-23}$ However, this route presents several complications, such as low yield, high cost, high reaction times, inhibition of the substrate, among others. ${ }^{22}$

The chemical route for 1,3-DHA synthesis from compound $\mathbf{2}$ is widely studied, once the direct and selective chemical oxidation of the adjacent hydroxyls of compound $\mathbf{2}$ is particularly difficult because of the similar reactivity. ${ }^{1-7}$

The synthesis of 1,3-DHA directly from 2 can be observed in several electrooxidation studies involving free or supported metal catalysts (nickel, platinum, palladium, silver, gold, etc.) or even some metallic alloys ( $\mathrm{Ni}-\mathrm{Cu}, \mathrm{Ni}$ $\mathrm{Co}, \mathrm{Ni}-\mathrm{Cr}, \mathrm{Ni}-\mathrm{Fe}$ and $\mathrm{Ni}-\mathrm{Mn}$ ). However, electrocatalytic oxidation using metals is expensive, besides provides catalyst deactivation by poisoning and presents high 
toxicity of transition metal catalysts. Usually, it was observed a low conversion combined with a high selectivity or high conversion together with low selectivity. ${ }^{24-39}$

Recently, Liu et al. ${ }^{40}$ reported the photoelectrochemical oxidation of 1,3-DHA directly from glycerol using nanoporous $\mathrm{BiVO}_{4}$, with high conversion and selectivity of $51 \%$. However, side products such as glyceric acid, formic acid, glycolic acid, $\mathrm{CO}_{2}, \mathrm{CO}$ and $\mathrm{H}_{2} \mathrm{O}_{2}$ and $\mathrm{O}_{2}$ were observed.

To the best of our knowledge, there are only three indirect routes to 1,3-DHA (1). Zheng et al..$^{41}$ performed glycerol acetalization, producing a 6:1 mixture of 5-hydroxy-2-phenyl-1,3-dioxane and (2-phenyl-1,3dioxolan-4-yl) methanol regioisomers, which were separated by recrystallization. Subsequently, oxidation of 5-hydroxy-2-phenyl-1,3-dioxane regioisomer, followed of acetal hydrolysis led to compound $\mathbf{1}$ after a recrystallization to separation of the benzaldehyde.

In another route, Jinjuan ${ }^{42}$ accomplished the tosylation of compound 2 to the 1,3-di-p-toluenesulfonyl-2-propanol, which was then oxidized in the presence of platinum as catalyst, furnishing the toluenesulfonyloxy-2-propanone intermediate. Next, this ketone was submitted to a nucleophilic substitution step, intermediate by hydroxide ions leading to $\mathbf{1}$.

Wang et al. ${ }^{43}$ reported the indirect synthesis of compound $\mathbf{1}$, via the conversion of compound $\mathbf{2}$ to 1,3-acetalized glycerol derivative, which was oxidized by Montanari oxidation system $(\mathrm{NaClO} / \mathrm{NaBr} /$ magnetic recyclable (2,2,6,6-tetramethylpiperidin-1-yl)oxyl (TEMPO)) followed by subsequent deprotection, furnishing the 1,3-DHA in good yield.

On the other hand, 1,3-dihaloacetones are used in organic synthesis as versatile building blocks for more complex molecules. ${ }^{44-57}$ Interestingly, they have been isolated from marine algae of the genus Asparagopsis taxiformis, A. armata and Falkenbergia rufolanosa. ${ }^{58,59}$ The 1,3-dichloroacetone is used in the synthesis of famotidine and citric acid and as substrate in crossed aldol condensation reactions. ${ }^{56,57}$ The 1,3-diiodoacetone has been used as a microbicide and algaecide for the treatment of industrial water since is not lacrimogenic as the 1,3-dibromoacetone. ${ }^{52}$ In addition, it is employed in organic synthesis for the construction of various heterocyclic systems through $\mathrm{S}$ - and $\mathrm{N}$-alkylation reactions. ${ }^{49-51}$ Many of these heterocyclic compounds exhibit analgesic, anti-inflammatory, antiviral, antihypertensive and antitumor activities. ${ }^{49-51}$ Already, the 1,3-dibromoacetone (7) has been used as raw material in the quinaldine derivative synthesis, a drug used in the treatment of acute asthma. ${ }^{45}$ In addition, compound $\mathbf{7}$ has been used in the synthesis of iminolactones (antibacterial), ${ }^{46}$ aldosterone inhibitors, ${ }^{47}$ vinylcyclopropane ${ }^{47}$ and propranolol hydrochloride (a drug used for heart treatment). ${ }^{48}$

In our continuing interest in the developing new routes for obtainment glycerol derivatives with high added value, ${ }^{11-14}$ we now wish to present reproductive synthetic routes to glycerol ketones 1,3-derivatives (1,3-dihydroxyacetone (1), 1,3-dichloroacetone (6), 1,3-dibromoacetone (7) and 1,3-diiodoacetone (8)) from bioglycerol, a green raw material. It is worth mentioning that these $\mathrm{C} 3$-ketones were synthesized via process intermediated by reagents supported on polymer resins or alumina, some of them under solvent free conditions.

\section{Results and Discussion}

Initially, the known Conant's methodology for regioselective chlorination of the glycerol was used. ${ }^{60}$ The 1,3-dichlorohydrin (3) was obtained in $80 \%$ yield after isolating (Scheme 1).

On the other hand, the 1,3-dibromohydrin (4) and 1,3-diiodohydrin (5) were prepared following the methodology developed recently for us, ${ }^{61}$ which consisted in the trans-halogenation of compound $\mathbf{3}$, in heterogeneous media, in the absence of solvent, using alumina-supported reagents $\mathrm{KBr} / \mathrm{Al}_{2} \mathrm{O}_{3}$ and $\mathrm{KI} / \mathrm{Al}_{2} \mathrm{O}_{3}$, respectively. High conversions were obtained, 77 and $98 \%$, respectively.

Next, the oxidation of compounds 3-5 to 1,3-dihaloacetones 6-8 was investigated using various oxidizing agents, firstly in homogeneous medium and using compound $\mathbf{3}$ as model (Table 1).

Initially, it was used the Steve Ley oxidation method ${ }^{62,63}$ (tetrapropylammonium perruthenate (TPAP)/molecular sieve $4 \AA / N$-methylmorpholine- $N$-oxide (NMO)), at room temperature, see entries 1,2 .

Several attempts of isolation of the reaction product, using silica gel or alumina column chromatography were unsuccessful since 1,3-dichloroacetone (6), or was retained on the column or eluted along with NMO due to their similar polarities (entries 1-2).

Next, it was used Corey's reagent, pyridinium chlorochromate (PCC), since it is a very efficient oxidation reagent to primary and secondary alcohols, ${ }^{64}$ (entry 3). However, the desired ketone 6 was obtained in only $30 \%$ yield. The reaction was purified by column chromatography using silica gel 230 to 400 mesh. Trying to improve the yield of the oxidation, the combination of PCC and periodic acid was utilized, since this reagent association produces periodate-chlorochromate, a more powerful oxidizing specie than the PCC alone. ${ }^{65}$ Indeed, the use of the catalyst system $\mathrm{H}_{5} \mathrm{IO}_{6} / \mathrm{PCC}$ increased the yield to $50 \%$ (entry 4). 


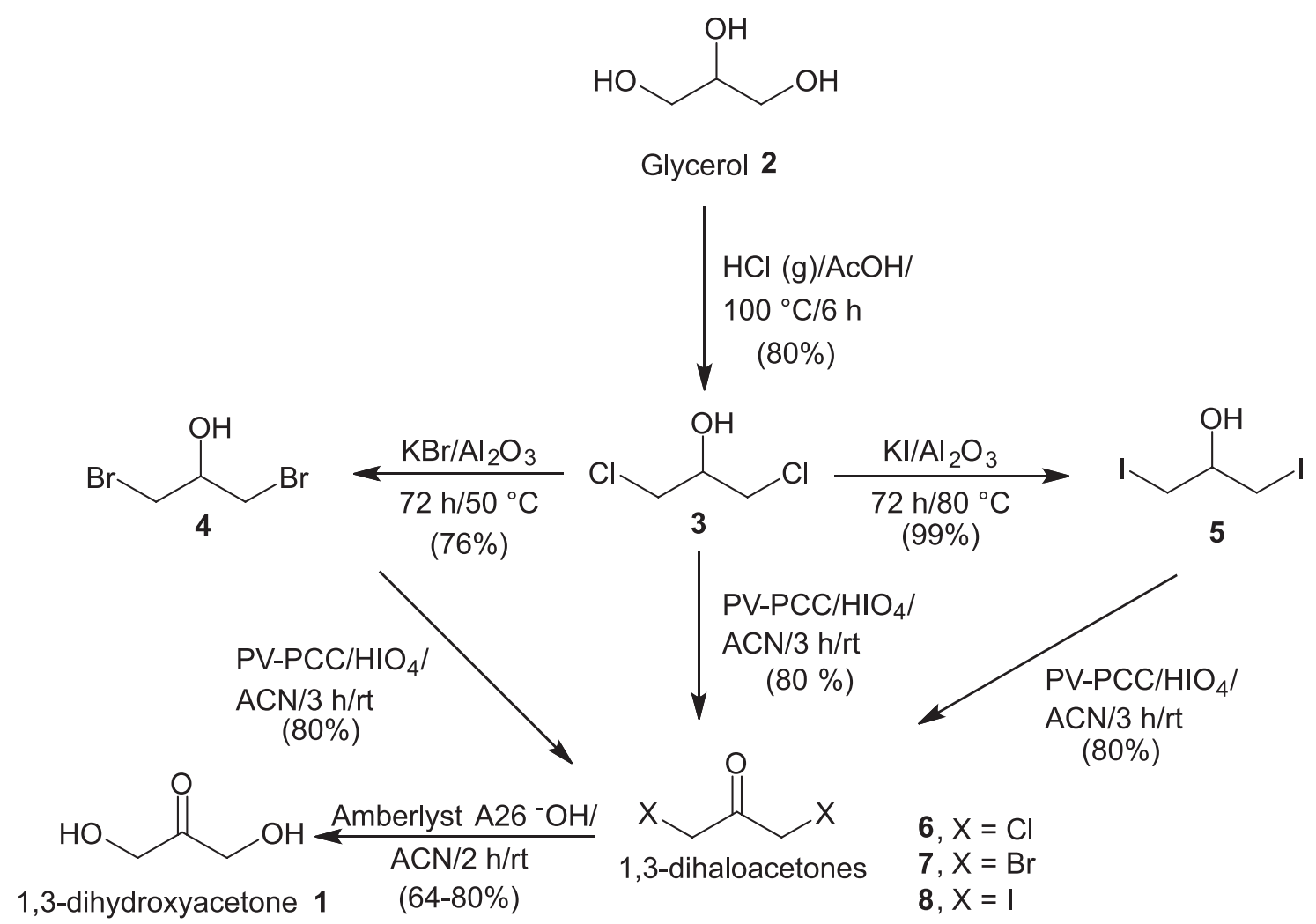

Scheme 1. Synthesis of compounds 1, 6-8 from glycerol (2).

Table 1. Oxidation reaction of 3 to 6 in homogeneous medium

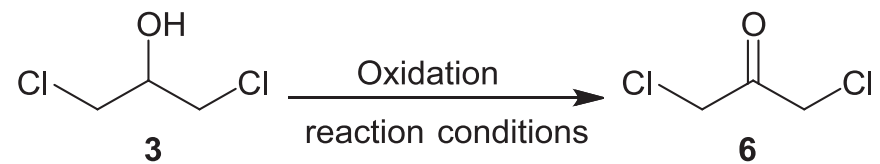

\begin{tabular}{|c|c|c|c|c|}
\hline entry & Oxidant/Co-oxidant (equiv.) & Solvent & time $/ \mathrm{h}$ & Yield / \% \\
\hline 1 & TPAP (0.04)/NMO (2.0) & a & 24 & $--^{\mathrm{b}}$ \\
\hline 2 & TPAP (0.1)/NMO (1.5) & a & 4 & $-^{c}$ \\
\hline 3 & PCC (1.5)/none & $\mathrm{CH}_{2} \mathrm{Cl}_{2}$ & 24 & 30 \\
\hline 4 & $\mathrm{PCC}(0.07) / \mathrm{H}_{5} \mathrm{IO}_{6}(1.5)$ & a & 24 & 50 \\
\hline
\end{tabular}

${ }^{a}$ Acetonitrile or 1,4-dioxane; ${ }^{b}$ no product was recovered after silica gel column filtration eluted with $\mathrm{Ac}_{2} \mathrm{OEt}$; ${ }^{\mathrm{c}}$ it was recovered a mixture of $\mathbf{6}$ and $\mathrm{NMO}$, after filtration through a short bed of silica gel eluted with AcOEt:MeOH, 95:5. TPAP: pyridinium chlorochromate; NMO: $N$-methylmorpholine- $N$-oxide; PCC: pyridinium chlorochromate.

In order to further improve the yield of the oxidation, it was theorized that the use of an oxidizing reagent supported in solid resin could minimize the isolation problems, since the product separation could proceed by a simple filtration of the heterogeneous phase, avoiding the retention of the product in the silica gel or alumina column chromatography, beyond simplify hugely the reaction work up (Table 2).

In this manner, it was tested the commercial oxidant polyvinyl-pyridinium chlorochromate (PV-PCC) at room temperature (entry 1). It was observed an improvement in the yield compared to oxidations realized with PCC and $\mathrm{PCC} / \mathrm{H}_{5} \mathrm{IO}_{6}$, in homogeneous medium (entry 1, Table 2 versus entries 3, 4, Table 1). Then, it was decided to heat the reaction based in $\mathrm{PCC} / \mathrm{H}_{5} \mathrm{IO}_{6}$ (entry 2). However, the heating at $80^{\circ} \mathrm{C}$ led to degradation of the solid reagent, decreasing strongly the yield.

The satisfactory result obtained by matching PCC with periodic acid, in homogeneous medium (entry 6 , Table 1), encouraged us to accomplish the reaction in heterogeneous medium with PV-PCC together with periodic acid (entry 3, Table 2). According to reports in the literature, ${ }^{66}$ it is suggested that a mechanism analogous to the homogeneous 
Table 2. Reaction of oxidation of compounds 3-5 to 6-8 in heterogeneous medium

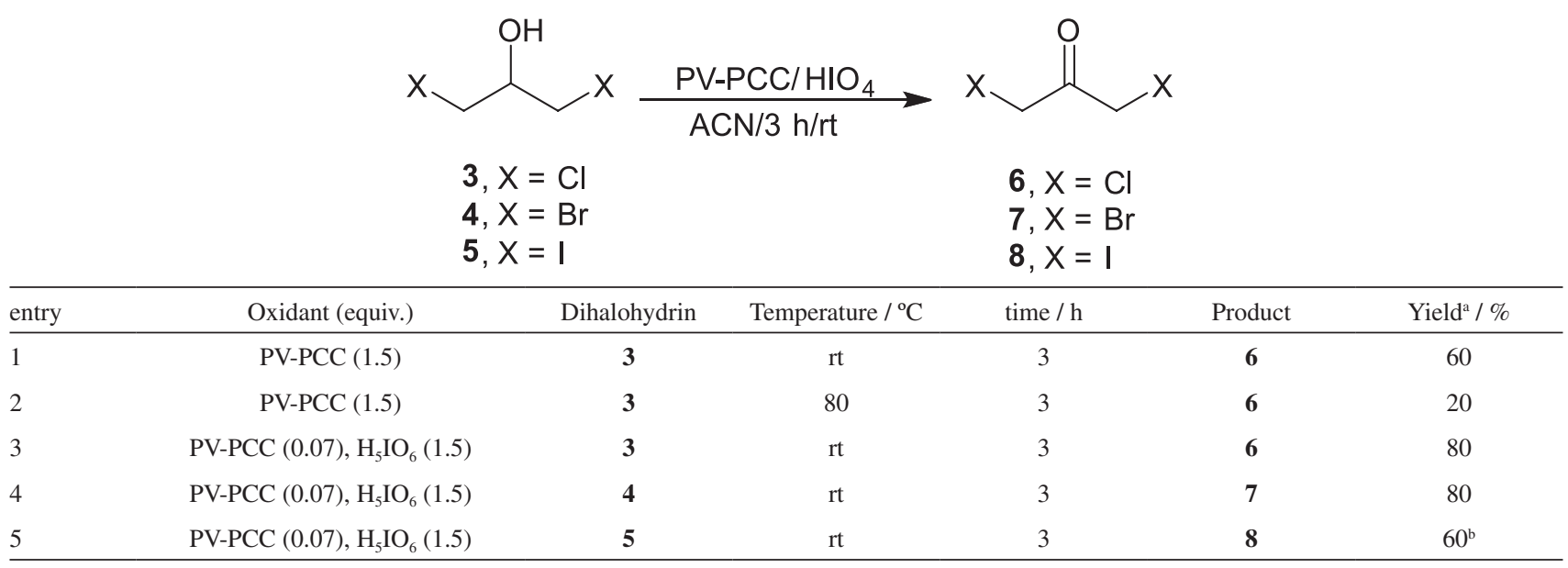

aProduct isolated after filtration on a column filled with $\mathrm{SiO}_{4} / \mathrm{Na}_{2} \mathrm{SO}_{3}$ solid; ${ }^{b}$ product isolated after liquid-liquid extraction. PV-PCC: polyvinyl pyridinium chlorochromate; rt: room temperature.

medium also occurs in a heterogeneous environment. As noted, the result was very good and 6 was obtained in $80 \%$ yield, as a crystalline solid, by simple filtration on a column filled with $\mathrm{SiO}_{4} / \mathrm{Na}_{2} \mathrm{SO}_{3}$ solid.

Similarly, the oxidation of 1,3-dibromohydrin 4 and 1,3-diiodohydrin 5 was mediated by PV-PCC resin (Table 2, entries 4 and 5). After 3 h none starting material was detected by thin layer chromatography and the desired 1,3-dihaloketones 7 and 8 were obtained in 80 and $60 \%$ yield, respectively. The lowest yield obtained for compound $\mathbf{8}$ probably occurred due to its high reactivity that caused its partial decomposition under the acidic conditions used.

With the 1,3-dihaloacetones 6-8 in hands, we left for the last step of the synthetic route proposed, which consisted in the nucleophilic substitution of the halogen atoms by hydroxyl groups ${ }^{67}$ (Scheme 1).

Thus, three equivalents of Amberlyst-A26 ${ }^{\mathrm{TM}}$ an ionexchange resin, source of hydroxide ions, was reacted with compound 6, using 1,4-dioxane as solvent in a reaction time ranging from $2 \mathrm{~h}$, at room temperature. However, the yield obtained to compound $\mathbf{1}$ was only $35 \%$.

The nature of the solvent showed great influence on the substitution performance. Thus, after various trials it was discovered that acetonitrile was the best solvent. The reaction was processed quickly $(2 \mathrm{~h})$ and cleanly at room temperature. A simple filtration led to the desired 1,3-dihydroxyketone $\mathbf{1}$ in $80 \%$ yield, as a dimeric crystalline solid. It is noteworthy that both reagents supported on resins can be regenerated by treatment with a $6 \mathrm{M} \mathrm{NaOH}$ solution (Amberlyst-A26 $6^{\mathrm{TM}}-\mathrm{OH}$ form) and a $2 \mathrm{M} \mathrm{CrO}_{3}$ solution (PV-PCC ${ }^{\mathrm{TM}}$ ).

It is important to mention that only in aqueous solution the dihydroxyacetone $\mathbf{1}$ is in the monomeric form due to its hydrated form $\mathrm{HOH}_{2} \mathrm{C}-\mathrm{C}(\mathrm{OH})_{2}-\mathrm{CH}_{2} \mathrm{OH}$. In other solvents, it is in the dimeric form, as can be evidenced by their ${ }^{1} \mathrm{H}$ and ${ }^{13} \mathrm{C}$ nuclear magnetic resonance (NMR) spectra, at $400 \mathrm{MHz}{ }^{68}$

Similarly, compounds $\mathbf{7}$ and $\mathbf{8}$ were transformed in $\mathbf{1}$, using Amberlyst ${ }^{\circledR} \mathrm{A} 26-\mathrm{OH}^{-}$form $/ \mathrm{CH}_{3} \mathrm{CN}$ in 64 and $66 \%$ yield, respectively (Scheme 1). It is worth mention that it was necessary the swelling of the Amberlyst-A26 $6^{\mathrm{TM}}-\mathrm{OH}$ form resin with acetonitrile and water $(5: 1)$ before reaction processing, in special if the resin was recently purchased..$^{69,70}$

\section{Conclusions}

Three efficient and reproducible approaches for the obtainment of the pharmochemicals 1,3-DHA $\mathbf{1}$, 1,3-dihalohydrins 3-5 and 1,3-dihaloacetones 6-8 from bioglycerol were developed. All new routes to production of the glycerol derivatives $(\mathbf{1}, \mathbf{6 - 8})$ were performed in heterogeneous medium, using reagents supported on resin polymer ( $\left.\mathrm{PV}-\mathrm{PCC}^{\mathrm{TM}}\right)$, ion exchange resin (Amberlyst ${ }^{\circledR} \mathrm{A} 26-\mathrm{OH}^{-}$form). In special, the indirect route to 1,3-DHA 1 developed for us, contrarily to direct routes mediated by different heterogeneous catalysts or selective microbiological oxidation does not suffer with problems of selectivity, conversion or reproducibility.

\section{Experimental}

\section{General remarks}

Glycerol (99.5\%), acetonitrile, $\mathrm{H}_{5} \mathrm{IO}_{6}, \mathrm{HCl} 36 \%$ (m/m) and glacial acetic acid all P.A./A.C.S. were purchased 
from Vetec Química Fina Ltda (Duque de Caxias, Brazil) and used as provided. Amberlyst ${ }^{\circledR} \mathrm{A} 26-\mathrm{OH}^{-}$form and Amberlyst ${ }^{\circledast} \mathrm{A} 26-\mathrm{HCrO}_{4}{ }^{-}$form were purchased from Sigma-Aldrich (Darmstadt, Germany) and readily utilized. The ${ }^{1} \mathrm{H}$ and ${ }^{13} \mathrm{C}$ NMR spectra were obtained on a Varian spectrometer (400 or $500 \mathrm{MHz}$ ), using tetramethylsilane (TMS) as the internal reference; the chemical shift values $(\sigma)$ were reported in ppm relative to TMS and values of coupling constants $(J)$ in Hz. Gas chromatography analyses were performed every $60 \mathrm{~min}$, using a gas chromatographic with flame ionization detection (GC-FID, Shimadzu GC-FID 2010; DB-1MS (100\% polydimethylsiloxane) fused silica capillary column $(30 \mathrm{~m} \times 0.25 \mathrm{~mm}$, film thickness $0.25 \mu \mathrm{m})$ ); carrier gas $\mathrm{H}_{2}\left(1.0 \mathrm{~mL} \mathrm{~min}^{-1}\right)$; temperature: injector $290{ }^{\circ} \mathrm{C}$, column oven $60-290{ }^{\circ} \mathrm{C}$ at $10^{\circ} \mathrm{C} \mathrm{min}^{-1}$, FID $290^{\circ} \mathrm{C}$ ). The gas chromatography mass spectrometry (GC-MS) analyses were conducted with a GC-MS Shimadzu QP500 instrument equipped with the same column used for the gas chromatograph.

\section{1,3-Dichloro-2-propanol (3) ${ }^{60}$}

${ }^{1} \mathrm{H}$ NMR (400 MHz, acetone- $d_{6}$ ) $\delta 3.70$ (sep, 4H), 4.08 (q, $1 \mathrm{H}), 4.70(\mathrm{~s}, 1 \mathrm{OH}) ;{ }^{13} \mathrm{C}$ NMR $\left(100 \mathrm{MHz}\right.$, acetone- $\left.d_{6}\right)$ $\delta 45.83$ (s, 2C), 70.70 (s, 1C); GC-MS (70 eV) $\mathrm{m} / z .43$ (45), 79 (100).

\section{Procedure to 1,3-dichloro-propanone (6) synthesis}

Orthoperiodic acid $\left(\mathrm{H}_{5} \mathrm{IO}_{6}, 0.529 \mathrm{~g}, 1.5 \mathrm{mmol}\right)$ and $10 \mathrm{~mL}$ of acetonitrile were added to a round bottom flask and stirred vigorously for $15 \mathrm{~min}$. Then $0.031 \mathrm{~g}$ $(0.07 \mathrm{mmol})$ of PV-PCC resin and $0.20 \mathrm{~g}(1.55 \mathrm{mmol})$ of 1,3-dichloropropanol $\mathbf{3}$ were added. The reaction medium was left under strong stirring for $3 \mathrm{~h}$. After, the reaction medium was filtered on a filter paper containing sodium sulfite, the solvent was evaporated and the residue purified over a short pad of silica gel/ $\mathrm{Na}_{2} \mathrm{SO}_{3}$, eluted with AcOEt/ methanol 95:5, yielding $0.158 \mathrm{~g}(80 \%)$ of 1,3-dichloro2-propanone $\mathbf{6}$, as a white crystalline solid.

${ }^{1} \mathrm{H}$ NMR (400 MHz, CD $\mathrm{CD}_{3} \mathrm{OD} \delta 3.28$ (s, 1OH), 4.43 (s, 4H); ${ }^{13} \mathrm{C}$ NMR (100 MHz, $\left.\mathrm{CD}_{3} \mathrm{OD}\right) \delta 43.73$ (s, 2C), 195.01 (s, 1C); GC-MS (70 eV) m/z 49 (65), 77 (100), 126 (15), 128 (10).

\section{Procedure to 1,3-dibromo-propanone (7) synthesis}

Orthoperiodic acid $\left(\mathrm{H}_{5} \mathrm{IO}_{6}, 0.529 \mathrm{~g}, 1.5 \mathrm{mmol}\right)$ and $10 \mathrm{~mL}$ of acetonitrile were added to a round bottom flask and stirred vigorously for $15 \mathrm{~min}$, then $0.031 \mathrm{~g}$ $(0.07 \mathrm{mmol})$ of PV-PCC resin and $0.33 \mathrm{~g}(1.5 \mathrm{mmol})$ of 1,3-dibromopropanol 4 were added. The reaction medium was left under strong stirring for $3 \mathrm{~h}$. After, the reaction medium was filtered on a filter paper, the solvent was evaporated and the residue purified over a short pad of silica gel $/ \mathrm{NaSO}_{3}$, yielding $0.26 \mathrm{~g}(80 \%)$ of 1,3 -dibromo2-propanone 7 , as a brown crystalline solid.

${ }^{1} \mathrm{H}$ NMR (400 MHz, $\left.\mathrm{CDCl}_{3}\right) \delta 4.18(\mathrm{~s}, 4 \mathrm{H}) ;{ }^{13} \mathrm{C}$ NMR $\left(100 \mathrm{MHz}, \mathrm{CDCl}_{3}\right) \delta 30.99$ (s, 2C), 193.70 (s, 1C).

\section{Procedure to 1,3-diiodo-propanone (8) synthesis}

To a round bottom flask was added periodic acid $\left(\mathrm{H}_{5} \mathrm{IO}_{6}, 0.529 \mathrm{~g}, 1.5 \mathrm{mmol}\right)$ and acetonitrile $(10 \mathrm{~mL})$. The suspension formed was stirred for $15 \mathrm{~min}$. Then, PV-PCC resin $(0.031 \mathrm{~g}, 0.07 \mathrm{mmol})$ and 1,3-diiodopropanol 5 $(0.32 \mathrm{~g}, 1.0 \mathrm{mmol})$ were added. The reaction medium was left under strong stirring for $3 \mathrm{~h}$. Next, the heterogeneous medium was filtered on a filter paper and the solvent evaporated, furnishing a viscous brownish liquid. Next, the liquid was diluted in ether $(20 \mathrm{~mL})$ and washed with a $\mathrm{Na}_{2} \mathrm{~S}_{2} \mathrm{O}_{3} 1 \%$ solution $(20 \mathrm{~mL})$. The organic phase was dried over anhydrous $\mathrm{Na}_{2} \mathrm{SO}_{4}$, filtered and concentrated under reduced pressure, affording the oxidation product $8(0.19 \mathrm{~g}$, $63 \%$ yield), as a yellow viscous liquid in satisfactory purity.

${ }^{1} \mathrm{H}$ NMR $\left(400 \mathrm{MHz}, \mathrm{CDCl}_{3}\right) \delta 4.23(\mathrm{~s}, 4 \mathrm{H}) ;{ }^{13} \mathrm{C} \mathrm{NMR}$ $\left(100 \mathrm{MHz}, \mathrm{CDCl}_{3}\right) \delta 1.96$ (s, 2C), 195.63 (s, 1C); GC-MS (70 eV) $\mathrm{m} / \mathrm{z} 141$ (45), 183 (100), 310 (45).

General procedure to 1,3-dihydroxyacetone (1) synthesis from 6-8

Amberlyst ${ }^{\circledR}$ A26- $\mathrm{OH}^{-}$form resin $(4 \mathrm{~g}, 3 \mathrm{mmol})$ was added to a round bottom flask of $50 \mathrm{~mL}$, then acetonitrile $(10 \mathrm{~mL})$ was added followed by 1,3-dichloro-propanone $\mathbf{6}$ $(0.20 \mathrm{~g}, 1.57 \mathrm{mmol})$. The reaction medium was stirred under magnetic stirring for $3 \mathrm{~h}$, at room temperature. The reaction medium was filtered through a simple funnel covered with filter paper and evaporated to give $0.113 \mathrm{~g}(80 \%)$ of the desired 1,3-DHA $\mathbf{1}$, as a dimer.

\section{Spectra data for the monomer 1}

${ }^{1} \mathrm{H}$ NMR $\left(500 \mathrm{MHz}, \mathrm{D}_{2} \mathrm{O}\right) \delta 3.56(\mathrm{~s}, 4 \mathrm{H}), 4.40(\mathrm{~s}, 4 \mathrm{H})$, 4.80 (s, 2OH); ${ }^{13} \mathrm{C}$ NMR (125 MHz, $\left.\mathrm{D}_{2} \mathrm{O}\right) \delta 66.52$ (s, 2C), 67.80 (s, 2C), 113.81 (s, 1C), 214.95 (s, 1C); GC-MS (70 eV) $\mathrm{m} / \mathrm{z} 42$ (100), 60 (45), 72 (40), 90 (5).

\section{Spectra data for the dimer of 1}

${ }^{1} \mathrm{H}$ NMR (400 MHz, CD 3 OD) $\delta 3.60(\mathrm{dd}, 8 \mathrm{H}), 4.87$ (s, $4 \mathrm{OH}) ;{ }^{13} \mathrm{C} \mathrm{NMR}\left(100 \mathrm{MHz}, \mathrm{CD}_{3} \mathrm{OD}\right) \delta 57.27$ (s, 2C), 58.06 (s, 2C), 101.03 (s, 2C).

\section{Supplementary Information}

Supplementary data are available free of charge at http://jbcs.sbq.org.br as PDF file. 


\section{Acknowledgments}

We thank CAPES and CNPq for fellowships for some authors.

\section{References}

1. Monteiro, M. R.; Kugelmeier, C. L.; Pinheiro, R. S.; Batalha, M. O.; César, S.; Renewable Sustainable Energy Rev. 2018, 88 , 109.

2. Bagnato, G.; Iulianelli, A.; Sanna, A.; Basile, A.; Membranes 2017, 7, 17.

3. Sun, D.; Yamada, Y.; Sato, S.; Ueda, W.; Green Chem. 2017, 19, 3186.

4. Mota, C. J. A.; Pinto, B. P.; Lima, A. L.; Glycerol: A Versatile Renewable Feedstock for the Chemical Industry; Springer International: Zurich, 2017.

5. Talebian-Kiakalaieh, A.; Amin, N.; Rajaei, K.; Tarighi, S.; Appl. Energy 2018, 230, 1347.

6. Nda-Umar, U. I.; Ramli, I.; Taufiq-Yap, Y. H.; Muhamad, E. N.; Catalysts 2019, 9, 15.

7. Nomanbhay, S.; Hussein, R.; Ong, M. Y.; Green Chem. Lett. Rev. 2018, 11, 135.

8. Luo, X.; Ge, X.; Cui, S.; Li, Y.; Bioresour. Technol. 2016, 215, 144.

9. Anitha, M.; Kamarudin, S. K.; Kofli, N. T.; Chem. Eng. J. 2016, 295, 119.

10. Kong, P. S.; Aroua, M. K.; Daud, W. M. A. W.; Renewable Sustainable Energy Rev. 2016, 63, 533.

11. Meireles, B. A.; Pereira, V. L. P.; J. Braz. Chem. Soc. 2013, $24,17$.

12. Meireles, B. A.; Pinto, S. C; Pereira, V. L. P.; Leitão, G. G.; J. Sep. Sci. 2011, 34, 971.

13. Nascimento, F. P. C.; Pereira, V. L. P.; BR Patent 102016 015956, 2016.

14. Dai, X.; Adomeit, S.; Rabeah, J.; Kreyenschulte, C.; Brückner, A.; Wang, H.; Shi, F.; Angew. Chem., Int. Ed. 2019, 131, 5305.

15. Katryniok, B.; Kimura, H.; Skrzynska, E.; Girardon, J. S.; Fongarland, P.; Capron, M.; Ducoulombier, R.; Mimura, N.; Paula, S.; Dumeignil, F.; Green Chem. 2011, 13, 1960.

16. Ciriminna, R.; Fidalgo, A.; Ilharco, L. M.; Pagliaro, M.; Open Chem. 2018, 7, 233.

17. Rajatanavin, N.; Suwanachote, S.; Kulkollakarn, S.; Int. J. Dermatol. 2008, 47, 402.

18. Wang, L. S.; Cheng, S. X.; Zhuo, R. X.; Polym. Bull. 2014, 71, 47.

19. Chênevert, R.; Caron, D.; Tetrahedron: Asymmetry 2002, 13, 339.

20. Dikshit, P. K.; Moholkar, V. S.; Bioresour. Technol. 2016, 216, 948.

21. Hu, Z. C.; Liu, Z. Q.; Zheng, Y. G.; Shen, Y. C. J.; J. Microbiol. Biotechnol. 2010, 20, 340.
22. Hu, Z. C.; Tian, S. Y.; Ruan, L. J.; Zheng, Y. G.; Bioresour. Technol. 2017, 233, 144.

23. Ma, L.; Lu, W.; Xia, Z.; Wen, J.; Biochem. Eng. J. 2010, 49, 61.

24. El Roz, A.; Fongarland, P.; Dumeignil, F.; Capron, M.; Front. Chem. 2019, 7, 156.

25. Houache, M. S. E.; Hughesa, K.; Baranova, E. A.; Sustainable Energy Fuels 2019, 8, DOI 10.1039/C9SE00108E.

26. Wang, X.; Wu, G.; Jin, T.; Xu, J.; Song, S.; Catalysts 2018, 8, 505.

27. Pembere, A. M.; Luo, Z.; Phys. Chem. Chem. Phys. 2017, 19, 6620.

28. Garcia, A. C.; Birdja, Y. Y.; Filho, G. T.; Koper, M. T. M.; J. Catal. 2017, 346, 117.

29. Sánchez, B. S.; Gross, M. S.; Querini, C. A.; Catal. Today 2017, 296, 35 .

30. Habibi, B.; Delnavaz, N.; RSC Adv. 2016, 6, 31797.

31. Crotti, C.; Farnetti, E.; J. Mol. Catal. A: Chem. 2015, 396, 353.

32. Hutchings, G.; J. Chem. Phys. 2003, 5, 1329.

33. Hirasawa, S.; Nakagawa, Y.; Tomishige, K.; Catal. Sci. Technol. 2012, 2, 1150.

34. Kwon, Y.; Birdja, Y.; Spanos, I.; Rodriguez, P.; Koper, M. T. M.; ACS Catal. 2012, 2, 759.

35. Dan, L.; Shiyu, C.; Jing, G.; Junhua, W.; Ping, C.; Zhaoyin, H.; Chin. J. Catal. 2011, 32, 1831.

36. Sivasakthi, P.; Sangaranarayanan, M. V.; New J. Chem. 2019, 43, 8352 .

37. Yan, H.; Yao, S.; Yin, B.; Liang, W.; Jin, X.; Feng, X.; Liu, Y.; Chen, X.; Yang, C.; Appl. Catal., B 2019, 259, 118070.

38. Yan, H.; Qin, H.; Feng, X.; Jin, X.; Liang, W.; Sheng, N.; Zhu, C.; Wang, H. M.; Yin, B.; Liu, Y. B.; Chen, X.; Yang, C.; J. Catal. 2019, 370, 434.

39. Zhou, Y.; Shen, Y.; Xi, J.; Luo, X.; ACS Appl. Mater. Interfaces 2019, 11, 28953.

40. Liu, D.; Liu, J. C.; Cai, W.; Ma, J.; Yang, H. B.; Xiao, H.; Li, J.; Xiong, Y.; Huang, Y.; Liu, B.; Nat. Commun. 2019, 10, DOI 10.1038/s41467-019-09788-5.

41. Zheng, Z.; Luo, M.; Yu, J.; Wang, J.; Ji, J.; Ind. Eng. Chem. Res. 2012, 51, 3715.

42. Jinjuan, W.; CN Patent 103.274911 A, 2013.

43. Wang, J.; Zhang, M.; Zheng, Z.; Yu, F.; Ji, J.; Chem. Eng. J. 2013, 229, 234.

44. Tormena, C. F.; Freitas, M. P.; Rittner, R.; Abraham, R. J.; J. Phys. Chem. A 2004, 108, 5161.

45. Brien, M. K. O.; Sledeski, A. W.; Truesdale, L. K.; Tetrahedron Lett. 1997, 38, 509.

46. Asghari, S.; Habibi, A. K.; Synth. Commun. 2012, 42, 2894.

47. Li, Q. Z.; Zhang, X.; Zeng, R.; Dai, Q.-S.; Liu, Y.; Shen, X.-D.; Leng, H. J.; Yang, K.-C.; Li, J.-L.; Org. Lett. 2018, 20, 3700.

48. Zhou, Y.; CN Patent 108586273 A, 2018.

49. Yarosh, N. O.; Zhilitskaya, L. V.; Shagun, L. G.; Dorofeev, I. A.; Russ. J. Org. Chem. 2014, 9, 1384. 
50. Dorofeev, I. A.; Shagun, L. G.; Zhilitskaya, L. V.; Yarosh, N. O.; Larina, L. I.; Chem. Heterocycl. Compd. 2018, 54, 550.

51. Shagun, L. G.; Dorofeev, I. A.; Zhilitskaya, L. V.; Yarosh, N. O.; Larina, L. I.; Chem. Heterocycl. Compd. 2017, 53, 920.

52. Rayudu, S. R.; EP 0313 272, 1988.

53. Vardanyan, R.; Hruby, V.; Synthesis of Essential Drugs, $1^{\text {st }}$ ed.; Elsevier Science: Maryland Heights, USA, 2006.

54. Apelblat, A.; Citric Acid; Springer International: Cham, Switzerland, 2014.

55. Li, H.; Zhang, T.; Zou, Y.; Wang, G.; Xiong, Y.; CN Patent 110015998, 2019.

56. Xu, Q.; Wu, S.; Huang, S.; Li, W.; Tang, J.; Yang, J.; Pat. WO $2019114258,2019$.

57. Hao, Q.; CN 107954847, 2018.

58. Wang, L.; Zhou, X.; Fredimoses, M.; Liao, S.; Liu, Y.; RSC Adv. 2014, 4, 57350.

59. Gribble, G. W.; Environ. Sci. Pollut. Res. 2000, 7, 37.

60. Conant, J. B.; Quayle, O. R.; Org. Synth., Coll. 1941, 1, 292.
61. Santos, P. F.; Silva, S. R. B.; Silva, F. P. N. R.; Costa, J. S.; Inada, J. S.; Pereira, V. L. P.; Green Chem. Lett. Rev. 2019, 12, 389.

62. Griffith, W. P.; Ley, S. V.; Whitcombe, G. P.; White, A. D.; J. Chem. Soc., Chem. Commun. 1987, 1625.

63. Ley, S. V.; Griffith, W. P.; Synthesis 1994, 639.

64. Corey, E. J.; Suggs, J. W.; Tetrahedron Lett. 1975, 31, 2647.

65. Hunsen, M.; Tetrahedron Lett. 2005, 46, 1651.

66. Alonso, D. M.; Granados, M. L.; Mariscal, R.; Douha, A.; J. Catal. 2009, 262, 18.

67. Waldmann, E.; Prey, V.; Monatsh. Chem. 1951, 82, 861.

68. Glushonok, G. K.; Glushonok, T. G.; Maslovskaya, L. A.; Shadyro, O. I.; Russ. J. Gen. Chem. 2003, 73, 1027.

69. Sherrington, D. C.; Chem. Commun. 1998, 2275.

70. Ley, S. V.; Baxendale, I. R.; Bream, R. N.; Jackson, P. S.; Leach, G. A.; Longbottom, D. A.; Nesi, M.; Scott, J. S.; Storer, R. I.; Taylor, J. S.; J. Chem. Soc., Perkin Trans.1 2000, 1, 3815.

Submitted: November 3, 2019

Published online: April 1, 2020 